\title{
LOS VALORES Y LA RESPONSABILIDAD EN LAS PRÁCTICAS EDUCATIVAS
}

\author{
Rubén Alberto Duarte Cuadros* \\ Universidad Libre \\ Universidad Autónoma de Colombia
}

\section{Resumen}

Es necesario reflexionar en torno al lugar que ocupan los valores éticos y ciudadanos, en especial, la responsabilidad en las prácticas educativas Es oportuno señalar que se hace indispensable aclarar el sentido y el contenido de lo que podemos entender por valores en su contexto social. En la educación en valores no puede reducirse a teorías sino que se encuentra ligado a prácticas institucionales y hace parte constitutiva de la evaluación institucional.

Palabras clave: ética, valores, evaluación institucional.

\section{Abstract}

The values and responsibility in educational practices.

It is necessary to reflect upon the place that ethical and citizen values occupy, in particular, on the place of responsibility in educational practices. For this, it is essential to clarify the meaning and the content of what we understand by values in their social context. Education in values cannot be reduced to theories, rather, it is linked to institutional practices and included in institutional assessment.

Key words: ethics, values, institutional assessment.

\section{INTRODUCCIÓN}

Frente a la educación debemos preguntarnos ¿qué valores deben comportar y fundamentarse desde la ética para el sistema de evaluación institucional de la educación en la universidad y el país? Cuando afirmamos que es necesario primero pensar qué valores deben fundamentar una ética en el sistema de evaluación, quiero referirme a la necesidad de aclarar el horizonte comprensivo de tal empeño, toda vez, que en materia de una teoría de la ética se requiere en principio definir el fundamento desde el cual pretendemos hablar, construir un discurso o instituir una práctica. En nuestro caso una práctica de evaluación educativa.

\footnotetext{
* Abogado y Filósofo, Especialista en Derecho Penal y Criminología, de la Universidad Libre; Magíster en Filosofía, de la Pontificia Universidad Javeriana; Candidato a Doctor en Derecho, de la Universidad Externado de Colombia rcuadros_filosofia@unilibre.edu.co
} 
Respecto al concepto de práctica tomaré como ejemplo el concepto de Michel Foucault, quien la ha definido como "la ritualización y regularidad de procedimientos y acciones que emergen en discontinuidades históricas, que a la vez instauran reglas, sistemas, normas y discursos, que se movilizan al interior de la sociedad, institucionalizando así, determinados hechos constitutivos del hacer humano"1. En este sentido quiero hoy pensar cómo es posible instaurar contenidos éticos en el hacer de una cultura de la evaluación educativa institucional con impacto social. Podemos decir que la educación se ocupa, por una parte, de construir y referirse a teorías y sistemas epistémicos comprensivos (producto del pensamiento y del conocimiento sistemático, como de las experiencias exitosas en el campo de la pedagogía), y de otra parte, debe poder dar cuenta del ethos de los procesos de socialización en los que se intersubjetivizan las acciones humanas en el mundo de la vida.

En este sentido, los conceptos, creencias y prejuicios que tengamos sobre la educación soportan un doble movimiento; en un primer momento tendríamos el sistema de conocimientos socialmente aceptado, estructurado, ritualizado e institucionalizado, tal y como se podría definir desde Michel Foucault, como práctica educativa, pedagógica, aceptada y regularizada por un sistema de normas que definiría los contenidos de la acción, encaminada a la educación instrumental y profesionalizante del hacer teórico; en un segundo momento, la exigencia que demandaría una educación para la acción integradora en la vida social, política, económica, ética y moral del país, en el que la comunidad políticamente organizada espera del sujeto formado teóricamente una coherencia en la vida practica de sus acciones.

Ahora bien, apoyándonos en Kant, podemos decir que la educación buscaría, en principio, desarrollar habilidades en el campo teórico comprensivo de la realidad, en la que cada institución educativa en un permanente estudio de sí misma, autoevalué su capacidad organizativa, institucional y vehiculizante de un saber científico, aceptado universalmente como saber crítico-reflexivo del estado del arte de las ciencias, sean estas exactas o sociales, desde una perspectiva analítico-epistémica. Por otra parte, la comprensión teóricoreflexiva de la realidad debe a la vez poder construir y vehiculizar una formación ética para la vida y la acción humana, en un mundo de la vida globalizado, en tanto incluye al otro en un permanente tejido social, que comporta la exigencia del poder dar cuenta del hacer cotidiano, político, familiar y social en general.

Así, una práctica de la evaluación educativa como cultura tiene la responsabilidad de autorregular sus propias prácticas teórico-científicas (principio de la autonomía) y, por supuesto, definir los marcos de referencia del encauzamiento de la acción humana encaminada a producir hombres capaces de autodefinirse como sujetos libres, autónomos, capaces de acción y lenguaje, como diría Habermas, para afrontar las expectativas de vida en un mundo del cual todos somos responsables de transformar en beneficio solidario y recíproco.

Al llegar a este punto, en el que se ha buscado esclarecer, en principio, una idea de práctica, y a la vez presentar dos movimientos o momentos que tiene la educación en el campo teórico y práctico, nos correspondería ahora pensar qué sería una educación ético-

\footnotetext{
${ }^{1}$ Michel Foucault. La Arqueología del saber. México: Siglo XXI, 1996, pág. 123.
} 
moral, y, más aún, qué significaría una práctica evaluativa en valores con carácter institucional y social.

Un lugar oportuno para comenzar nuestra indagación es la idea de ¿qué significaría una educación en valores?, un lema que está en el centro de nuestras prácticas pedagógicas, y,

en concreto, de lo que signifique la educación ético-moral en toda la práctica institucional educativa. Para referirme al desarrollo de este aspecto tomaré como referente directo un trabajo del profesor Carlos Thiebaut, de la Universidad Carlos III de Madrid, intitulado ¿Qué no es educar en valores?, presentado a modo de proyecto para la Cátedra Andina de Educación en Valores.

Lo primero que trataremos será una tarea de explicitación en torno a la pregunta ¿qué son los valores?, para lo cual presentaremos tres concepciones, que a la vez nos generan problemas en nuestras prácticas educativas, si de ellas no poseemos cierta comprensión, ya que los valores parecen ser grandes parámetros o modelos que empleamos en nuestros juicios para cualificar nuestras acciones. Por medio de ellos tipificamos lo que hacemos en categorías que generalmente son de carácter dicotómico como: lo bueno-lo malo, lo correcto-lo incorrecto, lo honesto-lo deshonesto, lo justo-lo injusto, etc., y en la medida que los aceptemos los incorporamos en nuestras acciones cotidianas, familiares, políticas y sociales, buscando de estos valores además la exigencia de otro valor como el de la coherencia en la acción.

Del principio de coherencia exigido para la acción, sacamos consecuencias y buscamos actuar de forma acorde con nuestras valoraciones, con nuestros juicios, e incluso en relación con el estilo de vida y modos de ser. Así, aprobamos lo que consideramos bueno y lo practicamos, a la vez, repudiamos lo que consideramos malo o deshonesto o injusto y generalmente lo rechazamos y corregimos. Esta es, por supuesto, una consideración muy general, sólo es un modo de exponer el problema, pero desde el punto de vista didáctico didáctico es muy provechoso decir que un valor es un modelo de acción que adoptamos a través de nuestros juicios y evaluaciones que hacemos de nuestro obrar cotidiano, social o político.

Ahora bien, la discusión sobre la naturaleza de los valores (¿qué tipo de entidades son?, ¿cuáles son sus funciones?, ¿cuáles los efectos de emplearlos?, etc.) ha sido un debate de nuestra cultura occidental desde la Antigua Grecia. Pero, sin remontarnos muy lejos en la historia y acudiendo a distintas concepciones que sobre los valores han existido y a las conclusiones de los debates de la contemporaneidad, podemos señalar tres grandes concepciones y resumirlas en tres posiciones claramente distinguibles en torno a la pregunta sobre los valores, a saber: 1) la concepción objetivista; 2) la concepción subjetivista, y 3) la concepción pragmática y racionalista. Considero que todo debate sobre los valores puede ser resumido en dichas concepciones, como señalaré a continuación.

\section{La concepción objetivista de los valores}


De manera importante se ha pensado que los valores son un tipo especial de "entidades" que tienen cierta existencia objetiva, y que, por ello, los enunciados en los que aparecen tienen valor cognoscitivo, de los que podemos emitir valoraciones de falibilidad y adecuación empírica conceptual, en el falseamiento o verificación de las proposiciones en las que aparecen los valores, al modo como acontece con los objetos de la naturaleza. Así, cuando decimos que mi amistad con aquella amiga con quien pasaba la tarde es un bien valioso, o que la responsabilidad de los políticos o la nuestra en lo que hacemos es una virtud deseable, parecería querer decir -según esta primera interpretación- que cualquier hablante competente sabe lo que quiere decir "amistad" o "responsabilidad" y que los enunciados que acabamos de formular y que incorporan esos valores son verdaderos.

Para esta primera posición y desde una perspectiva epistémica, que el hablante sepa lo que significan tales valores quiere decir que los aprehende de manera directa, que los valores conforman un estado de cosas, o son empíricamente existentes, y a la vez, por una suerte de capacidad de nuestra mente los aprehendemos, como las cosas que se dan en el mundo, a las que nos referimos de modo realista, y por analogía, pretendemos que los valores están en el mundo moral o mental como las cosas mismas y a ellos nos referimos.

Normalmente las concepciones objetivas y objetivantes, como la referida, se asocian a la vez a una concepción intuicionista, del cómo aprehendemos y usamos los valores. ¡Pero no ves que eso es malo para ti!, se exclama; podemos decir, por ejemplo, dando por sentado que aquel a quien nos dirigimos interpreta intuitivamente, o debería hacerlo en nuestro ejemplo, que en efecto, eso es malo para él. O, por poner otro ejemplo, podemos indicar: ¡con lo que hizo demostró una gran falta de honestidad! y, en la interpretación que estamos dando, parece que queremos decir que aquel comportamiento se relaciona negativamente con algo que llamamos honestidad y cuyo significado, de nuevo, damos por conocido intuitivamente por nuestro interlocutor y aun por nosotros mismos.

En realidad, no le faltan buenas razones a esta primera posición intuicionista y objetivista que hemos indicado. De hecho, una fuerte razón de apoyo sería que los valores tienen junto a su carácter objetivo un cierto carácter indefinible: no son cualidades o propiedades de las cosas que podamos describir; como lo señaló Moore a principios del siglo XX, cuando intentamos definir qué es bueno, siempre fracasamos y su significado parece escapársenos de las manos. Por ejemplo, si definimos que eso es bueno porque es útil, no deja de tener sentido seguir preguntando ¿por qué lo útil (o para el caso de lo bello, lo oportuno o lo conveniente) ha de ser bueno? Si tienen sentido estas preguntas, se observa que pueden remontarse ad infinitum, entonces, bueno es una cualidad indefinible, no reducible a otras propiedades de las cosas y de las acciones, y que consiguientemente lo que hacemos al emplear ese término calificativo de lo bueno es apelar a un valor que inmediatamente aprehendemos del modo que intuimos las cosas.

Esta razón a favor de la concepción objetivista es, no obstante, más una razón a favor de la indefinibilidad de los valores o de su no-reductibilidad a otras propiedades, que dicen más de lo que normalmente podemos decir de tal o cual valor. Aquí hay que estimar que la inmensa plasticidad de nuestro lenguaje y, por supuesto, del lenguaje moral, nos impide tener claro cuál sea el contenido en sí de un valor, como por ejemplo lo bueno, lo útil, lo bello, lo oportuno o lo deseable. Como veremos en un momento, la semántica de los 
valores ha variado o varía en el tiempo y en cada momento, nosotros cambiamos nuestros horizontes interpretativos y simbólicos significativos de los términos, que normalmente empleamos para calificar nuestros actos o acciones. Tal vez, lo más importante y significativo de nuestra reflexión es darnos cuenta de lo que hacemos cuando apelamos a un valor, en un juicio determinado de nuestras acciones. Como lo ha asumido Habermas:

La realidad con la que confrontamos nuestras oraciones no es una realidad "desnuda”, sino que ella misma está ya siempre impregnada lingüísticamente. La experiencia con la que controlamos nuestros supuestos está estructurada de forma lingüística e incrustada en contextos de acción. Tan pronto como reflexionamos sobre la pérdida de alguna certeza ingenuamente asumida ya no podemos encontrar ninguna clase de enunciados básicos que se legitimen "por sí mismos", es decir, ningún "principio” indudable más allá del lenguaje, ninguna experiencia evidente más acá de las razones. El concepto semántico-deductivo de fundamentación se nos queda corto; las cadenas de fundamentación retornan a los contextos de los que habían partido. La verdad de un enunciado parece que sólo puede ser garantizado por su coherencia con otros enunciados ya aceptados 2 .

Una importante consecuencia, que podemos deducir de esta concepción objetivista, es que los valores no pueden enseñarse o, mejor, que enseñarlos equivale sólo a que podemos mostrarlos y confiar que los otros los vean. En efecto, esta concepción objetivista de los valores nos conduce a pensar que las personas (los alumnos) deben ver el bien o, para el caso, los valores de fidelidad, honestidad o responsabilidad, y si no los ven, o no emiten los juicios adecuados o, sobre todo, porque lo que hacen no está de acuerdo con lo que ven o con lo que deberían ver, solo caben dos posibilidades: a) Algo falla en el sujeto o b) Algo falla en lo que debería ser visto (el valor).

Respecto de a) Algo falla en el sujeto, podemos aclararlo expresando que hay una falla en su proceso de socialización básica o alguna distinción psíquica es la causa de que no entienda qué es el bien, la fidelidad, la amistad o la responsabilidad, pero parece ser que si esos valores tienen realidad objetiva y que depende de cada sujeto el poderlos aprehender, será alguna falla en sus mecanismos de experiencia cognitiva e intuitiva lo que produce su incapacidad de verlos.

Cabe una segunda posibilidad respecto de b) Algo falla en lo que debería ser visto, aparentemente opuesta pero complementaria con lo que acabamos de decir en a). Cabe pensar, en efecto, que los valores mismos fallen, que ya no estén "ahî" y por esto mismo no puedan ser vistos o que, como vivimos tiempos cambiantes en nuestros lenguajes y prácticas morales, el valor ya no esté allí.

Existen importantes y clarificadoras teorías sobre qué significan los procesos de modernización, que pretenden enseñarnos que la modernidad ha dejado obsoletos muchos valores que algunos mayores todavía recordarán de la sociedad más tradicional en la que crecimos. Piénsese por ejemplo en todo el sistema de valores asociados a la sexualidad, como el valor "decencia" o el valor "fidelidad". Por mucho que instituciones tradicionales, como la Iglesia, o políticas conservadoras, como algunas contemporáneas en Estados Unidos, sigan apelando a esos valores, no podrá negarse, al menos, que el

\footnotetext{
${ }^{2}$ Jürgen Habermas. Verdad y Justificación. Madrid: Editorial Trotta, S.A. 2002. P. 47.
} 
contenido semántico de esos términos ha sufrido importantes cambios. Ni la nueva decencia es la anterior, ni probablemente tampoco lo sea la fidelidad, lo importante en cualquier caso es que determinados valores -el caso típico es el valor del honorpertenecen a mundos que se han alejado de nosotros. En este caso, no es posible socializar a los alumnos o a los ciudadanos en valores, porque no ven ya estos valores, por así decirlo, porque los valores se han esfumado.

Pero nótese que, tanto si es debido a una carencia en las capacidades experienciales e intuitivas de los sujetos o a una obsolescencia de los valores, estas dos posiciones pueden coincidir -a pesar de que los valores aparezcan en campos opuestos- en un diagnóstico normalmente pesimista sobre los tiempos que vivimos; solemos acudir a una muletilla para intentar explicarnos muchas quiebras en los procesos familiares y escolares de educación moral, hablamos con frecuencia de "crisis de valores", como si los niños (o sus familias) hubiesen dejado de ver la relevancia de determinados valores o como si esos valores (lamentablemente) hubiesen disminuido en su existencia hasta el punto de desaparecer.

¿Pero qué falla cuando los valores entran en crisis? Parece que la falla consiste en que nuestros juicios no se ejercen sobre lo mismo, o no hacen referencia a lo mismo, o bien, que perdiera consistencia el tejido social que se forma con nuestras interacciones y nuestras prácticas sociales y que alguna suerte de hecatombe es inminente. Cabe sugerir, para establecer un rápido diagnóstico opuesto al que nos conduce esta primera concepción de los valores, que cuando entran en crisis es que hemos dejado de juzgar adecuadamente nuestras acciones y, consiguientemente, andamos errados en ellas. Pero, para poder entender esta sugerencia, tendremos quizá que cambiar nuestra teoría de los valores.

No se negará que sea cierta esa sensación entre la perplejidad y el desánimo. Es, con probabilidad, una sensación auténtica de nuestro siglo, y a ella tendremos que darle alguna respuesta. Pero creemos que cabe sostener que la concepción sobre la que se apoya, una concepción objetivista de los valores e intuicionista del modo de aprehenderlos, es errada. Y, si lo es, será, por supuesto, también errada la práctica educativa de empeñarnos en enseñar que los valores están ahí, en el "mundo" (como si fueran objetos para un observador del que hipotéticamente construye una teoría de los valores) y que se pueden ver, o la práctica social que intenta restaurar un mundo valorativo que ha huido en el tiempo y en el espacio. Concebir así los valores es identificarlos demasiado con el mundo de las cosas. Una concepción objetivante de los valores, que los concibe como cosas u objetos que están ahí en el mundo, construye una aporía de la que Kant permanentemente nos exhortó a evadir:

Kant entiende que describimos el mundo desde perspectivas diferentes, como por ejemplo desde el punto de vista científico y desde el punto de vista moral, y que ninguna de las dos descripciones puede reducirse o intercambiarse por la otra; si bien creía -y pienso que tenía razón- que tanto nuestras imágenes morales como nuestras imágenes científicas pueden ser ambas correctas. Sin embargo, el mismo Kant estaba aún sujeto a una confusión: la de suponer que una descripción moldeada por nuestras elecciones conceptuales, de alguna forma no es, por esta misma razón, una descripción del objeto "como éste es en realidad". Tan pronto como cometemos este error abrimos las puertas al problema: "si nuestras descripciones son sólo nuestras descripciones, modeladas por nuestros intereses y nuestra 
naturaleza, ¿cuál es entonces la descripción de las cosas como ellas son en sí mismas?” Este término en sí "mismas" resulta totalmente vacuo: preguntarse cómo son las cosas "en sî" equivale, a estos efectos, a preguntarse cómo debe describirse el mundo en el lenguaje propio del mundo, cosa que no existe; solamente existe el lenguaje que nosotros, los seres hablantes, hemos inventado para nuestros diversificados puntos de vista ${ }^{3}$.

Podemos avanzar en un argumento más, en el que está implícita una concepción alternativa de la interpretación objetivante de la vida ética, que trataría de indicar por qué es un error concebir el mundo de los valores sobre el modelo del mundo de las cosas. Es un argumento sencillo: los enunciados morales que formulamos, como "eres responsable de lo que has hecho" o "es deshonesta esta conducta", no son verdaderos o falsos porque respondan adecuada o inadecuadamente a un mundo de valores vistos como objetos; son verdaderos o falsos (es decir, tienen valor cognoscitivo) porque responden a hechos y a acciones, por ejemplo, al hecho de que no cumpliste las expectativas normativas que sobre alguien se tenían y él debía, a su vez, tener, o a la acción que realizó y que según algún sistema normativo que compartimos, o deberíamos compartir, es una acción calificada de deshonesta. La concepción objetivista de los valores, llevada por el afán de darle un carácter objetivo y realista a nuestros juicios morales, yerra al fijar la dirección de ajuste de esos juicios; considerando que, al igual que existen cosas en el mundo y que nuestro conocimiento es verdadero si se adecúa a las cosas desde la tesis del representacionismo (filosofía de la representación), concluimos igual que existen, entonces, valores y que ellos deben adecuarse a nuestros juicios morales.

A este nivel de argumentación, por ejemplo, Habermas nos recuerda que si se llegase a tomar la decisión de pensar el mundo como algo constituido por objetos o bien por proposiciones, tendría graves consecuencias para la ontología, la teoría del conocimiento y los correspondientes conceptos de la verdad, toda vez, que:

Únicamente la presuposición realista de un mundo objetivo accesible intersubjetivamente puede hacer compatible la prioridad epistémica del horizonte del mundo de la vida articulado lingüísticamente y que no podemos traspasar- con la prioridad ontológica de una realidad independiente del lenguaje que impone limitaciones a nuestras prácticas ${ }^{4}$.

Aquí se hace necesario hacer algunas consideraciones, en tanto las prácticas de las conductas guiadas por reglas, sobre las cuales nos es posible entendernos, arrastra una confiada familiaridad con las generalidades existentes en un mundo de la vida, que se haya estructurado normativamente mediante reglas. La vida moral, podemos empezar a proponer, no es algo que se realiza, se vive o se actualiza porque se conozca, se conoce, más bien, porque se realiza. La primacía es la de la acción que realizamos en un mundo mediado ya lingüísticamente y configurado intersubjetivamente, no la del conocimiento que (decimos) tener de los valores vistos como objetos. O, digámoslo más radicalmente, la vida moral no existe si no la hacemos nosotros. No cabe pensar que exista en algún lugar un ámbito de valores que debe reflejarse, o puede no reflejarse, en el mundo de nuestros actos. Más bien, si no somos responsables de nuestros actos, no existe la responsabilidad de nuestras acciones; si no somos honestos, no existe la honestidad; si no somos justos, no

\footnotetext{
${ }^{3}$ Hilary Putnam. El Pragmatismo: Un Debate Abierto. Barcelona: Gedisa. 1999. p. 49.

${ }^{4}$ Jürgen Habermas. Op. cit., pp. 40-41.
} 
existe la justicia, etc. Los valores, en suma, no existen sino en, desde y para las acciones. Son, como dijimos más arriba, modelos o parámetros de nuestros juicios referidos a nuestras acciones, las que solo son posibles de ser compartidas de modo intersubjetivo, y mediadas pragmática y lingüísticamente por los sujetos poseedores de acción y lenguaje, como lo ha señalado Habermas.

\section{La concepción subjetivista de los valores}

El subjetivismo de los valores, parece, de entrada, opuesta a la objetivista que acabamos de comentar, pero coincide, curiosamente, con algunos de sus presupuestos, por ejemplo, frente al concepto intuicionista, que considera que los valores están ahí y que nosotros los intuimos por suerte de un acto representacionista. La concepción subjetivista sostiene que cuando apelamos a los valores para emitir juicios sobre nuestros actos, lo que hacemos es mostrar nuestras actitudes, básicamente emotivas ante esos actos. Mostramos en concreto nuestra aprobación e incitamos a otros a comportarse igual a como nosotros concebimos los valores.

Los valores serían, entonces, los nombres que les damos a esas actitudes básicas de aprobación. El valor de los valores -si se permite la redundancia- yace en su carácter fuertemente subjetivo. No es necesario que carguemos al término "subjetivo" de connotaciones individualistas, aunque esa puede ser una obvia manera de comprenderlo, puede entenderse también, en términos colectivos o culturales.

Cuando empleemos, según esta posibilidad, el término "deshonesto" o "responsabilidad" estaremos apelando a disposiciones o a reacciones anímicas y culturalmente conformadas. Un problema con el que se enfrenta la concepción subjetivista es que deja abierto el piso para el relativismo valorativo. $\mathrm{Si}$, tanto en términos individuales como colectivos, la apelación a valores es una apelación a disposiciones de los individuos, cabe la posibilidad de leer "esto es bueno" como resumen de "esto me parece bien a mí, o a nosotros, haz lo mismo.... pero tú verás".

Los enunciados valorativos no serían, en este caso, ni verdaderos ni falsos, sino, por así decirlo, meramente apelativos e instrumentales y, además, ligados a los gustos personales o colectivos, según el caso. El relativismo de los valores es una concepción corriente en nuestra cultura que se predica a sí misma hoy como posmoderna; el pluralismo de prácticas y de concepciones del bien o de la virtud y de concepciones del mundo parecería confirmar tales presupuestos. Pero cabe argumentar que el pluralismo estructural de concepciones del mundo, o de la vida, algo que es sustancial a la vida democrática, no tendría que conllevar una tesis relativista.

En efecto, la pluralidad de valoraciones puede responder a diferentes intereses prácticos, visiones del mundo y del conocimiento y no por esto arrastraría una presuposición relativista, porque incluso algunas visiones del mundo también se constituyen y configuran como absolutamente fundamentalistas, como omnicomprensiones de mundo, que como veremos en nuestro tercer modelo de comprensión de los valores, se pueden contrastar y validar por medio de razones y de argumentos. En este caso, pluralidad no equivale a "todo 
vale": vale lo que tengamos que justificar que vale; en este punto es conveniente tener presente a John Rawls, en particular lo fundamentado en Liberalismo Político y en Justicia como Equidad.

Existe, no obstante, una versión peculiar de una concepción subjetivista que trata de darle un giro realista para evitar esa molesta posibilidad relativista. Esta versión nos dirá que los valores son como las "cualidades secundarias" que poseen los objetos. Las cualidades secundarias -el ejemplo paradigmático es el color- son propiedades de nuestra percepción natural de los objetos, pero no propiedades de los objetos mismos. Una rosa no es primariamente roja: este color es la cualidad secundaria que, según nuestras disposiciones perceptivas, se suscita en nosotros ante determinadas maneras de reflejo de la luz en la rosa. Dejando de lado, ahora, si esta manera de concebir los colores es adecuada, y pensando más bien que sólo se buscaba una analogía ya conocida por todos, quienes defienden que los valores son equivalentes a las cualidades secundarias, lo que nos dicen es que los mismos son rasgos de la evaluación de actos que aparecen en nuestros juicios dadas naturalmente en nuestras disposiciones. Como se ve, las disposiciones pueden concebirse en términos naturalistas y no solo culturales o psíquicos.

Al igual que sucedía en la primera concepción objetivista, quienes defienden las diversas versiones de la segunda posición, subjetivista, que acabamos de mencionar, pensarán que la educación en valores tiene por objetivo suscitar en el alumno o en el sujeto la socialización de las adecuadas disposiciones y reacciones. Le invitamos a hacerlo, como vimos, cuando empleamos esos términos, y educamos su sensibilidad, sus reacciones, haciéndole partícipe de nuestras valoraciones. Más de nuevo, si se produjeran quiebras en ese aprendizaje, en ese proceso socializador, se responsabilizaría de nuevo al sujeto mismo o a los contenidos transmitidos. Algunos de estos, como nos acontecía al mencionar la primera posición, no podrían ya suscitar en él ni en nadie respuestas adecuadas.

Hagamos un trabajo de síntesis de lo visto hasta ahora. La primera concepción (objetivista) trataba, tal vez, de articular la intuición -que cabe pensar tenemos todos- de que cuando empleamos determinados términos valorativos queremos mostrar con ellos que las acciones son o no son de determinada manera, correctas o incorrectas, buenas o malas, justas e injustas, etc. Se encontraba, no obstante, con el problema de que, al concebir los valores como entidades peculiares objetivas (que poseen una estructura ontológica), las quiebras en los procesos educativos eran achacables, en su mayor parte, a los sujetos.

Curiosamente, la segunda opción (subjetivista), que pretende, por su parte, dar cuenta del hecho de que la vida moral tiene algo muy importante que ver con nuestras actitudes, entiende los valores solo como reacciones disposicionales de los sujetos, y coincidiría con el diagnóstico objetivista, en cuanto fallan los sujetos al no reaccionar adecuadamente al conjunto de valores de los que por su disposición están obligados a cumplir. Si la posición objetivista es, por así decirlo, ontológica, la segunda posición es básicamente conductista. La alternativa complementaria, que se puede definir como histórica o sociológica, en el análisis de esas fallas en la aprehensión ontológica o en la reacción subjetiva e intuitiva de los sujetos, indica que algo les puede pasar a los valores mismos, para no ser vistos o para no ser suscitados en nosotros de forma adecuada, como si la longitud de onda de la luz reflejada en la rosa no suscitara en nosotros la cualidad del rojo. 
Al presentar hasta aquí estos dos tipos de teorías, lo hacemos con el propósito de mostrar que determinadas concepciones sobre lo que son los valores -concepciones que han adquirido una cierta sistematicidad al elaborarse como teorías filosóficas- influyen sobre nuestras concepciones de educación moral, en nuestra condición de sujetos y ciudadanos, o de la educación "en valores". Esto nos lleva a concluir que cuando se producen quiebras en los procesos de transmisión de la visión moral que tuvieron generaciones anteriores, parecen achacables o bien a los sujetos educados, que ya no ven los valores, o bien a los valores, que han desaparecido.

Parece, no obstante, que, según lo dicho, esas quiebras sean achacables al proceso de transmisión de los sujetos socializadores y a lo que hacemos al educar, es decir, al proceso educativo. Ciertamente, podríamos modificar esas concepciones para dar cuenta de este nuevo problema e introducir alguna variante interesante, pero cabe argumentar que hacerlo supone, de manera importante, alterar la concepción misma que sobre los valores se sostiene en la sociedad y la cultura.

En efecto, la variante que habría que introducir tendría que adoptar la forma del argumento que antes presentamos, para mostrar dónde podría estar el error de la concepción objetivista de los valores. Si se trata de introducir al proceso de aprendizaje, para poderlo explicar por qué y cómo se producen quiebras en la educación moral, tendremos que acentuar que la moralidad no existe (no preexiste), sino que se hace. Se hace en procesos de argumentación que van ligados a un sistema de prácticas que se ritualizan, como lo ha pensado Foucault, o, atendiendo a Habermas, en procesos de intersubjetivización pragmática con recursos lingüísticos de entendimiento, que se producen en el mundo de la vida, y como se ha señalado, estas prácticas se regularizan en las acciones de modo argumentativo, que pueden producir dispositivos normativos que todos quisiéramos compartir de modo pragmático y racional.

Tomemos como caso los trabajos de la Pragmática Universal del Lenguaje, de Habermas, en la que se ha propuesto realizar una argumentación discursiva para enfrentar el caso de la Ética, la Moral, la Política y el Derecho, como sistemas regulativos de la acción de modo procedimental. Igualmente, cabe ahora argumentar añadiendo la perspectiva que nos suministra la posición subjetivista o conductista de la vida moral, y decir que esta tampoco existe, si no la hacen los sujetos que socializan (docentes) y los sujetos que son socializados (dicentes), en el ámbito de la educación y la cultura en general.

\section{La concepción pragmática-racional de los valores}

Para continuar e ir introduciendo la tercera concepción de los valores, que denominamos pragmática y racional, nos viene bien que empleemos ya, como foco de nuestra atención, ese peculiar valor que llamamos "responsabilidad". Para satisfacer tal pretensión permitámonos una breve consideración: aunque se ha mencionado el valor responsabilidad, es interesante observar que normalmente no le asignamos la misma importancia que a otros valores -como la honestidad, la fidelidad, la equidad, la decencia, la justicia, etc.-. Igualmente, parece que ha sido un concepto que no ha tenido gran fortuna en los grandes sistemas filosóficos modernos y contemporáneos, pero al contrario de lo que se presume del 
derecho, el valor responsabilidad es de una importancia tal, que sin él es casi imposible construir la teoría de la responsabilidad civil y penal, que se fundamenta en términos kantianos en el concepto de libertad y autonomía, con base en nuestra condición antropológica de sujetos racionales, que nos permite constituirnos en autolegisladores de nuestras acciones morales.

Todo esto es paradójico, porque el concepto de responsabilidad es, probablemente, a la vez, el más antiguo (arcaico), en el sentido de originario y básico; nuestros conceptos morales, pues, aparecen como condición de muchos de nuestros juicios morales, y el que más recientemente ha sido tematizado como concepto moral (pensemos, por ejemplo, en la "ética de la responsabilidad" de Max Weber). Tal vez sea un concepto ético relativamente reciente $-\mathrm{y}$ sujeto a muchos malos entendidos- porque sus perfiles son algo borrosos. Al menos, su necesaria borrosidad aparece en cuatro dimensiones.

Primero, en un criterio de temporalidad, que se refiere tanto a la responsabilidad por algo hecho en el pasado ("eres responsable de esto que has hecho") como de algo que debe ser hecho en el futuro ("nuestra responsabilidad de legarle a las generaciones futuras un mundo habitable"), es decir, se aplica tanto a las causas de lo hecho, como a las consecuencias de lo que deberíamos hacer.

Segundo, la noción de responsabilidad parece nacer de la necesidad de enjuiciar negativamente lo hecho o lo por hacer; la atribución de responsabilidad -como la de culpa o desaprobación- nace de la imputación a alguien del peso posible de una acción y parece conllevar, por ello, una forma de sanción o de juicio crítico. En términos de la acción futura, indica, a su vez, la posibilidad de imputar desaprobación o culpa por no llevar a cabo la expectativa racionalmente sustentada y justificada de lo que debería ser hecho. Pues bien, parecía que este elemento de sanción crítica es, por una parte, más cercano a las prácticas de nuestros juicios cotidianos, pero, a la vez, más alusivo para las teorías éticas que sostenemos. Aunque nos parece más difícil definir qué es bueno, qué es malo, en la experiencia directa, paradójicamente a los sistemas éticos -hasta la modernidad- les ha sido a veces más fácil diseñar utopías que perfilar la crítica de sus respectivos presentes.

Tercero, el concepto de responsabilidad tiene una peculiar estructura recursiva; no solo nos consideramos responsables de lo que hacemos, sino de lo que creemos que debemos hacer; no solo de lo que hemos hecho, sino de lo que deberíamos haber hecho. Con esta estructura recursiva, lingüística y racional, el concepto de responsabilidad se muestra, de nuevo, como un concepto básico para la capacidad de juzgar la acción; es la categoría normativa del juicio de toda acción posible. Pero, por ello mismo, siendo un concepto de uso inmediato, tiene un campo amplísimo de aplicación, atañe a lo pasado, a lo futuro y a lo posible.

Cuarto, el concepto de responsabilidad no sólo se aplica a los individuos; también hablamos, con significado, de responsabilidades colectivas, que nos sumergen con frecuencia en grandes perplejidades.

Los cuatros rasgos mencionados -temporalidad abierta, negatividad, recursividad y carácter tanto individual como colectivo del agente al que se le ha de realizar una imputación, entendida como el cargar una acción a alguien, en tanto sujeto racional e imputable- son 
claramente modernos: la idea misma de la temporalidad histórica, el juicio crítico sobre los procesos sociales y lo que hemos empezado a denominar barbaries -como genocidios, exterminios, etc.-, la reflexibilidad y el carácter colectivo de las acciones sociales son rasgos que han definido de distintas maneras la modernidad reciente.

Regresemos a lo dicho, al curso de nuestra reflexión. ¿Es la responsabilidad un valor que pudiera ser interpretado con el modelo objetivo y el modelo subjetivo? Parecería que sí: podríamos suponerle una cierta cualidad indefinible -su borrosidad se prestaría a ello-, que inmediatamente debería ser aprendido por todos; parecería también que es posible comprenderla como una noción que empleamos para aprobar o reprochar acciones -ese es su carácter crítico- y que lo que queremos y creemos es que nuestro juicio crítico sea compartido.

Pero explicitemos primero que el concepto de responsabilidad es algo que patentemente atribuimos cuando enjuiciamos y que, por consiguiente, es esa capacidad de juzgar la que explica y hace posible la valoración que nuestro juicio comporta. El vínculo inmediato entre la noción de responsabilidad y el que está es atribuida a alguien -de algo y por algoen un juicio que se pone de relieve, así que, tal vez, le acontezca lo mismo a todo valor; estos no son tanto entidades peculiares o reacciones disposicionales, sino que, como hemos querido sostener, "parámetros de nuestros juicios, maneras en las que enjuiciamos". Y notemos, segundo, que como su estructura recursiva mostraba, no sólo atribuimos responsabilidad por lo hecho o por lo hacer, sino por el juicio mismo que deberíamos hacer. No sólo somos morales porque seamos responsables de nuestras acciones, sino por juzgar moralmente el mundo que hacemos. El poder juzgar nuestros actos, y el deber de actuar nos constituye moralmente. Al menos estos dos rasgos nos constituyen moralmente como sujetos de acción y lenguaje, y parecen requerir un modelo distinto de comprender la vida moral y los valores.

Este tercer modelo, que hemos denominado pragmático, por el acento en las acciones y prácticas en un mundo mediado ya lingüística e intersubjetivamente, y racional, por el acento en el juicio que emitimos a través de procesos recursivos de entendimiento, como lo habíamos señalado arriba, a propósito de la discursividad argumentativa de corte pragmático -tipo Habermas, Jonh Rawls e incluso hoy Hilary Putnam- nos lleva a una manera distinta de entender la vida moral y, sobre todo, la educación en valores, en contextos de enseñanza-aprendizaje del sistema educativo nacional.

Así, educar en valores no es transmitir conocimientos sobre peculiares entidades -como si estas existieran en un mundo posible y ontológico-, ni suscitar determinadas respuestas comportamentales. Es, más bien, la más compleja, pero más posible, tarea: la de transmitir $\mathrm{y}$ suscitar estructuras racionales de juicio, realizar y posibilitar el uso racional y argumentativo de comprensión del mundo de la vida, que se encuentra ya estructurado lingüísticamente; pensemos en la teoría del juicio ético y estético en Kant, como posibilidad de pensar la moral en tanto somos sujetos libres, autónomos y racionales.

¿Cómo enseñar, entonces, el valor responsabilidad? Parece que un camino adecuado sería analizar conductas y realizar sobre ellas juicios normativos. Esto implica tres cosas: en primer lugar, ejercer la responsabilidad de juzgar conductas moralmente relevantes (o 
descubrir lo que moralmente es relevante y pueda ser descrito como referencia en las prácticas sociales y culturales, en las que se encuentran vinculadas nuestras acciones en el mundo de la vida). La educación moral conlleva, entonces, la socialización en el juicio de acciones que tienen relevancia moral, en las que aparece algo que nos implica especialmente de manera normativa. Propondría que esta relevancia moral viene incorporada en nuestra sociedad, definida por dos parámetros cruciales: acciones y prácticas que suscitan cuestiones de importancia desde una teoría de principios y valores, como exigencias de justicia, equidad y dignidad humana (del tipo Rawls, Dworkin y Habermas, entre otros, que apelan a lo razonable de las acciones y de las prácticas sociales, en aquello que todos quisiéramos que fuera justo, equitativo o digno para todos) y acciones prácticas que suscitan cuestiones de comprensión de las diferencias valorativas mismas, es decir, de tolerancia. Desde esta perspectiva, educar moralmente es, en primer lugar, socializar en problemas, a la luz de la búsqueda resolutiva de problemas con recursos racionales dialógicos, en cuyo análisis intervendrán valoraciones y todo el conjunto de principios, normas y razones que se emplean en la práctica de los juicios.

Es adecuado ahora retornar, brevemente, a las anteriores alusiones sobre la crisis de valores. Estos, dijimos, tienen una semántica históricamente cambiante -algunos se hacen obsoletos, como el honor, y otros cambian de significado, como la decencia. Pero, decíamos, cuando se menciona una crisis de valores parece apuntarse a una quiebra en el tejido social. ¿Cómo interpretar esta quiebra desde este tercer modelo? Como una ausencia de los juicios morales relevantes para juzgar prácticas quizá ya no adecuadas, a la altura de las circunstancias, unos juicios que deberían determinar qué otras acciones, racionalmente justificadas, debiéramos llevar a cabo. El argumento conservador por un mundo de valores ido, desvanecido, encubre y oculta la gran ausencia que se esconde tras la llamada "crisis de valores": la ausencia de prácticas justas y de nuestros juicios de corrección normativa, frente a las injusticias e iniquidad existente social y culturalmente.

En segundo lugar, educar moralmente es educar en razonamientos sobre esas acciones. Si se han propuesto grandes parámetros -como la justicia, la equidad, la dignidad humana y la tolerancia-, la sugerencia está, a su vez, apoyada recursivamente en razones. Se puede argumentar, como han hecho las grandes teorías contemporáneas de la justicia, la equidad, la dignidad humana y la tolerancia, que esos son los problemas relevantes en nuestras sociedades, tanto a nivel macro como a nivel micro. Pero no solo se trataría de justificar la elección de esos parámetros: educar en la responsabilidad solo parece ser posible si al juzgar las acciones damos razones -referidas a sus causas, referidas a sus efectos- de sus valoraciones, etc. Decimos que tal acto o tal institución nos parece injusta o que tal otro comportamiento es intolerante porque $\mathrm{x}, \mathrm{y}, \mathrm{z}$, damos aquí una razón o una serie de ellas en las que, de nuevo, intervendrán los principios o las normas que sean relevantes. Partir de las acciones y analizar las razones de estas no es solo apelar a valoraciones y a disposiciones. Más claramente, es ejercitar la racionalidad que nos hace ser humanos.

En tercer lugar, educar moralmente en los términos que hemos referido es educar en la autonomía y la libertad predicable a todo ser racional, tal y como lo asume Kant. Que una razón sea válida significa, sobre todo, que es válida para el sujeto que la emplea. Cuando enjuiciamos, y damos razones de nuestros juicios y valoraciones, que entendemos válidos, lo que intentamos es no decir que eso "es válido para mí", sino decir que "esta razón es 
válida" y lo puede ser para todos, en tanto somos seres racionales poseedores de lenguaje y entendimiento. En este modo de entendernos no podemos sustituir al otro en el enjuiciamiento de esa validez. Si es una razón para él, será él mismo el que la toma como válida. ¿Y qué -podría también preguntarse- si no es una razón válida para él? ¿No es, precisamente, ese el problema de la educación moral? En efecto, ese es el gran problema. Pues suele suceder que, por múltiples causas -desde el pluralismo de concepciones del mundo que es un rasgo estructural de nuestras sociedades, hasta discrepancias en los análisis de causas y efectos de las acciones-, lo que tomamos como una razón válida no sea concebido así por los otros. Pero, entonces, este tercer rasgo de la responsabilidad pasa a primer plano, y nos remite al primero: somos, también -y quizá sobre todo- responsables de nuestras discrepancias, de las razones de nuestras discrepancias, de las razones que apoyan nuestros juicios discrepantes o de disenso.

Quien disiente de nosotros -imaginemos, un alumno- no es un sujeto moral sólo porque discrepe: lo es si se responsabiliza y porque se responsabiliza de sus juicios disidentes. Esa es, precisamente, su autonomía. La educación moral, así vista, es una educación en la autonomía y para la libertad, cuando, incluso, se presenta como una educación en la responsabilidad por los disentimientos y los desacuerdos. Educar en la responsabilidad nos conduce a pensarnos responsables de las primeras tanto como de las segundas. Esa forma de educación parece ser la única que permite que entendamos que la democracia es algo más que un sistema de gobierno: es una forma autónoma de responsabilizarnos de nuestras opciones y de presentarlas en el espacio público, construyéndolo precisamente, como público, es decir, como espacio de todos y de cada uno, en el que libremente disponemos del mundo que queremos, y autónoma y responsablemente lo construimos en nuestras practicas educativas. En este punto me gustaría dejar, a modo de tentación, el que reflexionemos precisamente en ¿qué es la ilustración?, ¿que es una sociedad ilustrada? y ¿qué sería una educación para la ilustración?, si no precisamente la construcción de un espacio público en el que todos demos razones y argumentemos del modo y expectativa de vida a la que aspiramos, y en la que como hombres libres nos pensemos.

\section{Conclusiones}

Luego de haber abordado estos tres modelos generales de comprensión de los valores, con la idea básica de aclarar el horizonte para pensar una práctica evaluativa de la educación y señalar que al parecer sólo sería posible desde el modelo pragmático-racional, en tanto, es un modelo que asume para sí el principio de la responsabilidad de nuestras acciones, en atención a predicarnos como sujetos libres y autónomos, que tenemos posibilidades de emitir juicios y valoraciones de nuestras acciones de modo argumentativo, que nos permite incorporar sentido a nuestras prácticas educativas, consolidando así, como valor, "la responsabilidad de nuestro hacer y quehacer educativo e institucional", pensemos por ejemplo: cómo Habermas concibe que una teoría dialógica del discurso sólo es posible si aceptamos que el hombre debe ser visto en términos de un sujeto libre, autónomo y reflexivo, capaz de dar cuenta argumentativamente de su personalidad y de las acciones que realiza para sí (ideales que puede justificar) y para los otros (asumir una actitud de solidaridad y reconocimiento de la alteridad). En síntesis, una cultura de la evaluación educativa es al final de cuentas: un caso de responsabilidad individual de sus agentes $e$ institucional de la comunidad" que produce opinión pública. 


\section{Bibliografía}

APEL, Kart-Otto. Estudios Éticos. Buenos Aires: Distribuciones Fontamara, S.A. 2004. Teoría de la Verdad y Ética del Discurso. Barcelona: Ediciones Paidós / I.C.E.U.A.B. 1998.

DWORKIN, Ronald. M. El Imperio de la Justicia. Barcelona: Editorial Gedisa, S.A. 1988. La Filosofía del Derecho. México, D. F.: Fondo de Cultura Económica. 1980.

HABERMAS, Jürgen. Aclaración a la Ética del Discurso. Madrid: Editorial Trotta, S.A. 2000.

. El Occidente Escindido. Madrid: Editorial Trotta, S.A. 2006.

. Facticidad y Validez. Madrid: Editorial Trotta, S.A. 2001.

. Fragmentos Filosófico-Teológicos. Madrid: Editorial Trotta, 1999. . Más allá del Estado Nacional. Madrid: Editorial Trotta, 1998.

. Tiempo de Transiciones. Madrid: Editorial Trotta, 2004. Verdad y Justificación. Madrid: Editorial Trotta, 2002.

HaRT, H. L. A. El Concepto de Derecho. Buenos Aires: Abeledo - Perrot. 1998.

KANT, Immanuel. Fundamentación de la Metafísica de las Costumbres. Barcelona: Editorial Ariel, 1999. . La Metafísica de las Costumbres. Barcelona: Ediciones Altaya, 1993. . Critica de la Razón Pura. México: Editorial Porrúa, 1987.

Putnam, Hilary. El Pragmatismo. Barcelona: Editorial Gedisa, 1999. Razón, Verdad e Historia. Madrid: Editorial Tecnos (Grupo Anaya S.A.). 2006. . El Desplome de la Dicotomía Hecho-Valor y otros ensayos. Barcelona: Ediciones Paidós. 2004. y Habermas, Jürgen. Normas y Valores. Madrid: Editorial Trotta. 2008.

RAWLS, John. La Justicia como Equidad. Barcelona: Ediciones Paidós Ibérica, 2002. . Liberalismo Político. México: Fondo de Cultura Económica. 1996. . Teoría de la Justicia. México: Fondo de Cultura Económica. 1997.

Thebaut, Carlos. ¿Qué no es Educar en Valores? Conferencia Presentada para la Cátedra Andina de Educación en Valores. 